\title{
Principles of Sustaining Partnerships between Higher Education and their Larger Communities: Perspectives from Engineering Faculty Engaged in Learning through Service
}

\author{
Bowa George Tucker* \\ James B. Francis College of Engineering \\ University of Massachusetts Lowell \\ Lowell, Massachusetts 01854 \\ Bowa_Tucker@uml.edu \\ Angela R Bielefeldt \\ Department of Civil, Environmental, and \\ Architectural Engineering \\ University of Colorado Boulder \\ Boulder, Colorado 80309 \\ Angela.Bielefeldt@colorado.edu \\ Olga Pierrakos \\ Department of Engineering \\ James Madison University \\ Harrisonburg, VA 22807 \\ pierraox@jmu.edu
}

\author{
David O Kazmer \\ Department of Plastics Engineering \\ University of Massachusetts Lowell \\ Lowell, Massachusetts 01854 \\ David_Kazmer@uml.edu \\ Kurt Paterson \\ Department of Engineering \\ James Madison University \\ Harrisonburg, VA 22807 \\ paterskg@jmu.edu \\ Annie Soisson \\ Center for the Enhancement of Learning and Teaching \\ Tufts University \\ Medford, Massachusetts 02155 \\ Annie.Soisson@tufts.edu
}

Chris Swan

Department of Civil and Environmental Engineering

Tufts University

Medford, Massachusetts 02155

Chris.Swan@tufts.edu

* Corresponding author

Abstract - With the increased focus on community engagement in higher education, engineering faculty members are using Learning through Service (LTS) as a viable way of providing a platform for interactive participatory student learning and involvement in the community. By engaging students to learn in the community, the creation of knowledge shifts from the classroom to the community. This paper explores how LTS engineering practitioners from a diverse range of institutions use LTS to engage community partners in the co-creation of knowledge. Twenty-seven interviews were conducted with these faculty members to identify best practices for mutually beneficial partnership with the communities they serve. Analysis of the interview transcripts reveals six guiding principles of effective and sustainable community partnerships: 1) understand the needs of the community, 2) seek community feedback through direct interaction, 3) engage community partners from an asset-based viewpoint, 4) use cultural intermediaries in international LTS efforts, 5) deliver useful projects, and 6) sustain long-term relationships to improve project outcomes.

Index Terms - learning through service, engineering education, community partnerships, faculty careers 


\section{INTRODUCTION}

The Kellogg Commission of 1996 was formed to create awareness, particularly among public universities, of the need to reform in ways that will help them fulfill their public service role. ${ }^{1}$ The commission of presidents and chancellors from twenty-five major public universities, concluded that higher education institutions should not only offer programs that prepared students to respond effectively to the complex issues of the society they will enter, but also that colleges and universities must themselves respond to the social and economic needs of the communities they serve Colleges and universities have been challenged in the past decade to become engaged in their communities and to prepare "students for responsible and satisfying lives in a pluralistic society" through the continuing mission of Campus Compact. ${ }^{2}$

Further recognizing this important mission, the Carnegie Foundation for the Advancement of Teaching in 2006 began an elective "community engagement classification" that recognized institutions of higher education for curricular engagement and outreach partnership. While the Carnegie designation was based on voluntary participation, the criteria for designation were based on having demonstrated teaching, learning, and scholarly actions that deepen students' academic learning in collaboration with their communities in a mutually beneficial way to enrich the scholarship of the institution. ${ }^{3}$ A key element of the relationship between higher education and their larger communities is the mutually beneficial exchange of knowledge and resources within the framework of partnership and reciprocity (CFA, 2008). Within the context of this partnership, the community is viewed as possessing assets rather than from a deficit-based model. Hess, for instance, posit "the basis of service-learning is often a deficit model where students view themselves as the advantaged providing a service to those who society has deemed disadvantaged." As such, instead of focusing on the deficiencies of the community, the community is viewed as having a repository of knowledge that contributes to the learning process. Strand advances the notion that the partnership is intended to democratize the production and control of knowledge by involving community partners in the process of discovery of new knowledge to improve the lives of those in the community. ${ }^{5}$

In light of these developments, there have been numerous calls to reform engineering education in the United States to incorporate increasing student capacity for understanding the impact of engineering solutions within a global and societal context. ${ }^{6-8}$ With this increased focus on preparing engineering students to be socially responsible, faculty members are challenged to develop curricular and extracurricular activities to enable their students to develop learning outcomes essential in addressing the challenges of the twenty-first century such as globalization, climate change, sustainability, and inequality. ${ }^{9}$

As Tsang postulates, this paradigm shift in engineering curriculum requires students to develop "professional skills" that include collaborative active learning, communication, leadership, and the ability to function in diverse and cross cultural environments. ${ }^{10}$ In essence, "professional skills" demand that students develop the ability to listen, negotiate, ask the right questions to acquire information, and analyze and synthesize information through critical thinking with regards to social issues. These are skills that are necessary to function in a deliberative democracy that fosters community dialogue. Hence, the reform efforts shifted the focus not only on the way engineering students are taught necessary technical skills to address the demands of a changing technological society, but also toward developing the skills needed to be effective professional engineers in a globalized world. As such, Learning through Service (LTS) has been integrated into some engineering education programs (curricular and 
extracurricular) as an essential strategy to move students "from technocrats to true professionals". 11

\section{What is Learning through Service?}

Learning through Service is an all-encompassing term to include a wide range of curricular to extracurricular community learning environments. For instance, service-learning is a curricular teaching method in which students participate in an organized service activity for academic credit that meets identified community issues. Reflection by the students on their service experience furthers their understanding of course content. ${ }^{12-17}$ Additionally, extracurricular community learning activities consist of informal yet intentional learning opportunities external to academic course work. These include global learning opportunities, such as Engineers without Borders (EWB), Humanitarian Technology Challenge (HTC), and Body of Knowledge (BOK). ${ }^{18}$

Unlike the primary use of lectures in teaching, LTS include aspects of experiential education, collaborative learning, problem-based learning, and service-learning. Colby suggests that these pedagogies tend to intersect with each other and therefore are not mutually exclusive. ${ }^{19}$ In problem-based learning, students' learning is organized around studying and providing potential solutions for real world problems; in service-learning, students learn through hands-on activities that connect theory in real-life settings. Therefore, both the curricular and extracurricular activities, can in fact, be considered a form of community service. Howard describes Service to the Community as work to "improve the quality of life for an individual, group, neighborhood, or for the entire community". ${ }^{20}$ Moreover, Hepburn states, the difference between community service and service-learning is that "service-learning is a particular form of community service that is curriculum-based," whereas "community service is broadly used to describe all types of service including individual and organized volunteer work that is not part of the school curriculum". ${ }^{21}$ Also, curriculum designs for service-learning differ from one to another. Enos and Troppe describe a typical model in which service-learning can consist of a one-time service immersion experience followed by a short reflective essay or work in the community as the major focus of the course and student work. ${ }^{22}$ Nevertheless, community service projects must be relevant and meaningful and worthwhile to the community and the students. The service project must allow the students to find meaning and through which knowledge may be created and internalized.

\section{Theoretical Basis of Learning through Service}

Giles and Eyler (1994) argue that Dewey's educational and social philosophy provides the foundation that is necessary to generate specific questions within a consistent theoretical framework relevant to service-learning and other forms of experiential education. ${ }^{23}$ Dewey's educational and social philosophy is based on a theory of knowledge that is directly linked to problems that arise from human experience. ${ }^{24-26}$ Dewey suggests that knowing is a matter of creating rather than finding meaning. Thus, he rejects the spectator view of knowing which suggests that learners are passively involved in the learning process. From Dewey's viewpoint, the role of human experience in learning is not only critical, but also useful in terms of developing the capacity of people to work together to solve societal problems. 
Campbell describes Dewey's educational and social philosophy as one which furthers the welfare of mankind in a democratic society and not a search for a final truth or a fixed reality. ${ }^{27}$ This view places considerable value on the contributions of individuals as participants in problem solving for collective action for the greater good in a democratic society. It is a view of learning that combines intellectual knowledge with skills that are associated with citizenship. The aim is to engage learners beyond academic studies and prepare them for engagement in solving social problems.

Learning through service has proliferated in higher education as a powerful teaching and learning method to meet the challenges required for an engaged institution of higher education, and to prepare students with the skills needed to address the challenges of social ills in a globalized world. ${ }^{28}$ Consequently, many colleges and universities have increased learning through service opportunities for engineering students through curricular and extra-curricular programs. ${ }^{29-32}$

The theoretical basis of faculty community engagement efforts is that the learning process is a learner-centered approach that is jointly constructed by students, community members and faculty members. ${ }^{33,34}$ The learning is viewed from a complex lens that takes into account the importance of meaning, context, students, community members, and faculty members. Ideally, the learning is a democratic learner-centered approach in which students work in collaboration with the each other, community members and their instructors to alleviate community problems. While these pedagogies continue to gain momentum in higher education, very little is known about how engineering programs in higher education engage their community partners in a common effort to identify solutions to pressing societal problems.

The framework adopted for this study is drawn from the "Community of Practice" (CoP) model $^{35}$ and social constructivist learning theory. ${ }^{36}$ CoP model is used to understand the structure of engineering faculty community engagement practice. $\mathrm{CoP}$ is a group learning process that enables individuals to share information and experiences with others within the group. The group often emerges on the basis of common interest to gain knowledge about "a set of problems or a passion about a topic". ${ }^{37}$ The learning process enables group members to enhance their learning by intermingling on a continuing basis. Wenger (1998) advances three dimensions of CoP that describes what it is (domain), how it functions (community), and what it produces (practice). ${ }^{37}$ Lave \& Wenger (1991) argue that the learning process must evolve within that community. ${ }^{38}$ Hence, constructivist learning theory is useful to understand the effect of individuals learning from others within a group. ${ }^{38}$ This learning is viewed as socially constructed and takes into account the importance of meaning, context, situated knowledge, the individual, the community, the teacher, etc. ${ }^{39}$ The learning process consists of incorporating new knowledge with prior knowledge and allows the individual to constantly construct and reconstruct knowledge.

The value of this theoretical approach is that it focuses on a learning environment in which learners work in collaboration with others to solve problems. The approach enables group members to contribute to the learning process, and to participate in decisions that affect them personally and professionally. ${ }^{40}$ Finally, it provides situations for learners to develop habits of reflective thinking that enable them to make informed decisions about social actions. ${ }^{24}$ 


\section{Research Questions ANd PurPose}

In 2011, investigators from Tufts University, James Madison University, Michigan Technological University, the University of Colorado Boulder, and the University of Massachusetts Lowell were awarded a grant from the National Science Foundation to evaluate the impacts on faculty currently engaged in Learning through Service efforts (LTS). Another goal of this grant was to use the findings to subsequently empower additional faculty to implement LTS. Expectations included supporting faculty engaged in LTS efforts in engineering in order to expand the list of appropriate teaching, learning, and assessment methodologies that are appropriate to enhance engineering education. This paper explores how engineering faculty members from a diverse range of institutions use LTS to engage community partners in the cocreation of knowledge. The primary research question is:

\section{How do LTS faculty practitioners and community partners engage to establish an effective LTS} community of practice?

The purpose of this study is to a) identify the characteristics of effective community partnerships from the perspectives of engineering faculty members involved in LTS efforts, and to b) develop best practice models on the basis of partnership initiatives between engineering faculty practitioners of LTS and their community partners. Several studies have been done on service provided to community partners in engineering, ${ }^{40-42}$ A gap in the literature exists focused on a comprehensive strategy to describe how engineering faculty should go about establishing community partnerships. This paper aims to investigate the dimensions of sustainable community partnerships with community partners. Table 1 provides the research question and sample interview questions.

\section{TABLE I}

\section{SAMPLE INTERVIEW QUESTIONS MAPPED TO THE RESEARCH QUESTION}

\begin{tabular}{ll}
\hline Research Question & Pertinent Interview Questions \\
\hline How do LTS faculty practitioners and & - How did you become interested in using LTS? \\
community partners engage to establish an & - What curricular unit does the LTS project tie into? \\
effective LTS community of practice? & - Can you explain how you are using LTS in \\
& extracurricular programs? \\
& - Do you receive any help from community partners? \\
\hline
\end{tabular}

\section{METHODOLOGY}

\section{Use of the Case Study Method}

A case study approach as qualitative research method is used to present basic information where little research has been conducted, to provide detail account of phenomena, and to focus on process rather than outcomes. Therefore, case study as a qualitative research technique is used for this research primarily because it provides "a detailed account of the phenomenon under study". 43 Yin posits that the case study method is the preferred strategy when "how or why" questions are being posed. Furthermore, he suggests that the case study method is used in many 
situations to contribute to understanding individuals, groups, and organizational, social, political, and related phenomena. ${ }^{44} \mathrm{He}$ also approaches case study as a comprehensive research strategy that covers logic of design, data collection techniques, and specific approaches to data analysis. He states that "the following five components of a research design are especially important: a study's research question; its propositions, if any; its unit(s) of analysis; the logic linking the data to the preposition; and the criteria for interpreting the findings" (p. 21).

Therefore, case study as a qualitative research technique is used for this research primarily because it provides "a detailed account of the phenomenon under study". 45 The unit of analysis in this study is engineering faculty engaged in LTC efforts with community partners. Hence, indepth interviews of 27 engineering faculty members were conducted using a semi-structured protocol. According to this protocol, the participants were each interviewed once with the use of a digital recorder. The interview data was subsequently transcribed after all the participants were interviewed.

\section{Participants and Recruitment}

All of the participants were involved in workshops designed by investigators. Eleven of the interviews were conducted face-to-face for approximately forty-five minutes at an "expert meeting" for experienced LTS faculty practitioners, and the rest of the interviews were done over the phone with participants who attended subsequent workshops on the basis of the issues related to the implementation of LTS that were identified at the "expert meeting." The workshop participants were partially selected based on the LTS activity that they proposed to implement or enhance at their institution. The participants taught courses from various engineering departments (mechanical; computer and electrical; environmental; civil; biomedical), some of which were interdisciplinary. The LTS courses ranged from freshmen seminars to mostly design courses.

With regard to the type of LTS, Figures 1(a) and (b) provide a characterization of LTS activities by types of communities served and type of curricular integration. There were slightly more faculty engaged in international than domestic activities though a significant number of faculty were engaged in both domestic and international service. From a curricular perspective, a majority of the faculty interviewed incorporated service into their academic coursework, though a significant number of faculty performed extracurricular service solely or in addition to curricular implementations. 


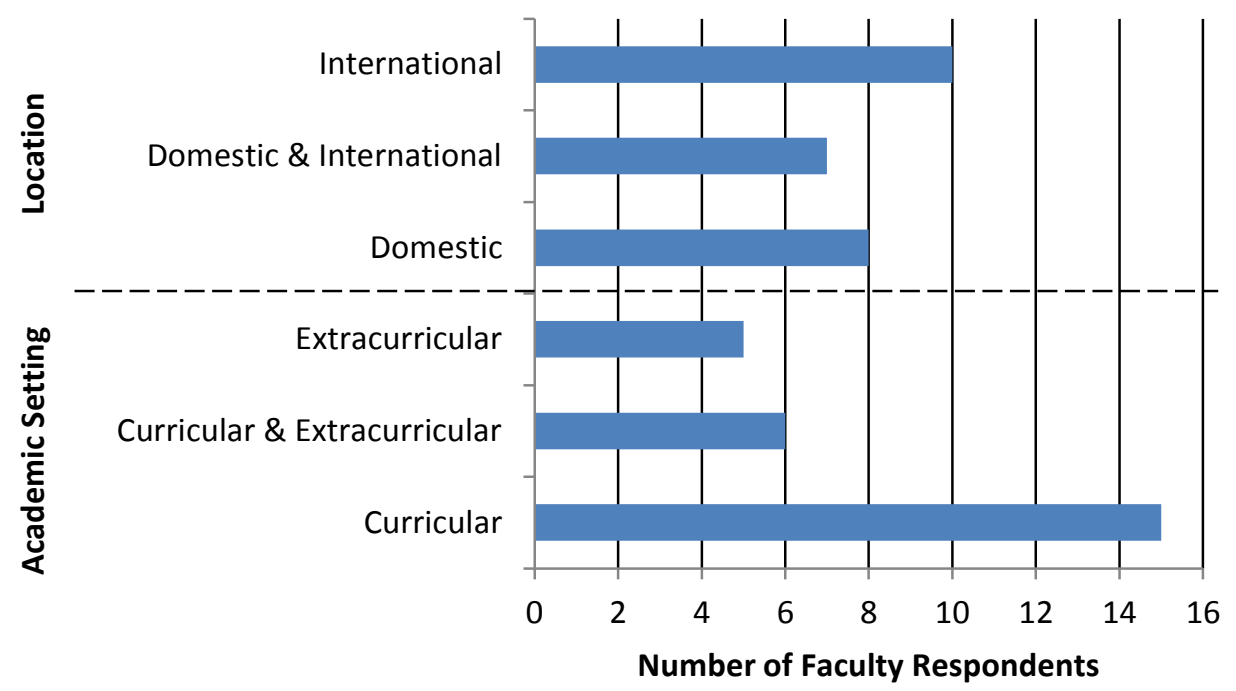

FIGURE I

CHARACTERIZATION OF LTS ACTIVITIES BY (A, LEFT) TYPES OF COMMUNITIES SERVED, AND (B, RIGHT) TYPE OF CURRICULAR INTEGRATION

In terms of the participants' gender, seven of the 27 faculty interviewed were female, corresponding to $25.9 \%$. With respect to rank, sixteen of the 27 participants were tenured, while six were on tenure track but without tenure. Two of the interviewed instructors were not tenuretrack while one was administrative and two had a mixed faculty/administrative appointment. Sixteen of the participants had five or more years of experience with LTS. A majority (20) of the 27 faculty members were engaged at research doctoral degree granting institutions (RD) with only a few at research masters (RM) or undergraduate teaching institutions. Seventeen of the faculty members were employed at public institutions, and ten of the 27 faculty members were employed at private institutions. Only three of the 27 participants indicated that more than half of their departmental faculty were engaged in LTS supporting the notion that LTS activities are generally practiced by a minority of faculty.

\section{Data Analysis}

Analysis of the data began by reading all the interview transcripts. This process was repeated three times to gain familiarity with the data. This was useful in identifying the initial codes by highlighting sentences from the text that appeared to be emerging into themes. An independent researcher developed a coding framework by noting common thematic threads surfacing in the responses. A second researcher read the transcripts and identified emerging themes. The themes were compared with the independent researchers coding framework, and equivalent results were noted with $90 \%$ inter-rater reliability. The final coding framework was established and used to code the data into thematic groups. In order to help organize the emerging themes, thematic network analysis, recommended by Attride-Stirling for interpreting complex qualitative data, ${ }^{46}$ was deemed most appropriate. This allowed for the systematic extraction of common themes and evaluation of the relative importance of each. 


\section{FINDINGS}

The analysis reveals six key guidelines that emerged from the interview data with respect to their interaction with community partners: 1) understand the needs of the community, 2) seek community feedback through direct interaction, 3) engage community partners from an assetbased viewpoint, 4) use cultural intermediaries in international LTS efforts, 5) deliver useful projects, and 6) sustain long-term relationships improves project outcomes. Each of these guidelines is next discussed.

\section{1) Understand the Needs of the Community}

The means and importance of understanding the needs of the community was found to vary somewhat with respect to curricular and extracurricular LTS efforts. For the majority of the faculty involved in LTS curricular efforts, analysis of the interview data indicates that engineering design courses provide a powerful opportunity to engage community partners. Their design courses provided a way of enabling students to understand and address the needs of the community while working collaboratively in the learning process with their community partners.

Human-centered design is an approach to design that takes into considerable account the people or end-user for which they are designing. The design approach involves the development of an in-depth understanding of the needs of the user, and invariably the involvement of the user in the design process. Zoltowski et al. argue that while human centered design poses challenges for faculty, it can contribute to innovation in engineering design and improve acceptance of new products. ${ }^{47}$ It was not surprising that engineering faculty were aware of the utility of humancentered design in the design process when applied to LTS course projects.

The first step in human-centered design is to understand the needs of the user. One faculty member states:

"We use the human centered design model. So it's actually integrated in the curriculum and the community, the stakeholders who are the community. In human centered design, understanding of and interacting with the stakeholders is one of the pillars with human centered design and by placing the human centered design model in service learning the students are doing that all the time."

Another faculty states:

"what we're seeing is that students are starting to embed components of I guess you could say human center design within the process, and that's sort of the avenue that we're going down in terms of trying to get our students to identify, not only just the need for designing for a human, but realizing that it's not always about creating the next iPhone."

In comparing the way students approach the design process, another faculty points to a study that compared the design approach of students in their program to students that were not part of their program:

"One of the interesting things that the study showed is that if you look at how students approached the engineering design process, if you compared students who had been in [a service-based project] to students who had not been in [non-service-based project] you see a difference in their interest, taking interest in the client before they actually go into design. So, people who had [service-based projects] tend to be much more interested in listening to the client and understanding the client issues before doing the design." 
Zoltowski et al. suggest that design is central to engineering education and one of the essential criteria that should be used for evaluating and accrediting engineering programs. ${ }^{48}$ Therefore, the use of a human centered model in LTS projects ensures that faculty and students work in collaboration with community partners to adequately understand the needs of the community in order to create an appreciated and useable end product. Hence, students using LTS projects with input from the community partner and end-users during the design process should lead to solutions with reduced cost and increased user satisfaction.

Similarly, some of the faculty respondents mentioned the use of systems analysis in the design process to understand the needs of the community. One faculty states:

"It's actually kind of easy because one of the principals of systems analysis is to understand the stakeholder, the position of the needs of the stakeholder when you gather the requirements for the system, so one of the - if you're building something for an organization's needs, you have to understand the perspective of the organization. You know, you have to build for them; you can't build what you might want or what you - you know, might be ideal in an all possible world because it's not all possible; it's bound by their reality. So, I mean, it's - it emphasizes it pretty quickly, just as a principal of the field."

Here again, the methods used in the design courses provided the means to involve community partners in a collaborative learning process with students. The approach requires students to become more engaged with their community partners in order to learn about the partners' needs and at the same time consider the input of the communities in the engineering solutions that they develop.

Faculty involved in extra-curricular programs primarily described Engineers without Borders-USA (EWB-USA) as their primary source of involvement. One faculty explains the program structure of their EWB activities by stating:

"The way that we run our EWB program here places quite a strong emphasis on understanding the community before trying to come up with a solution...students are aware that we need to be addressing the community's needs, and they also recognize that that's the only way that we can get big projects done is to have community buy-in, which comes from addressing community needs."

With respect to LTS project engagement, another faculty states:

"We really encourage the students and the faculty members to engage in the communities where they're working. They also typically will engage with an NGO [non-governmental organization] contact who has some familiarity with that community or region. We will also have them often times interact with university partners in that region. So usually those interactions are what helps sensitize students to the particular, you know, social or community needs or problems that those communities are having."

Both of these comments suggest that EWB is purposefully designed to ensure that students understand the needs of the community, since that community input is essential in developing reasonable and sustainable solutions to address the community needs. Accordingly, the emergent principle "Understand the Needs of the Community" was consistent across both curricular and extra-curricular engineering LTS programs. 


\section{2) Seek Community Feedback through Direct Interaction}

A key benefit that emerged from the interviews was the impact that community feedback had on the design and implementation of the engineering projects. One faculty states:

"You can tell that there were components to the design that were actually changed and impacted. And I talked to them (students) a little bit about their process and how they had to continually go back and change things based on the user feedback. And we're not talking about technical user feedback here; we're talking about someone sitting down and looking at it, using it and saying this just doesn't work."

Another faculty spoke to the need for direct rater rather than passive engagement by the community partner:

"What I believe is the most effective way to implement a Learning Through Service opportunity is when you can bring an actual partnership vs. "We need a client, you're going to be our client", and that client just really isn't involved. You know, we talked earlier about how that actual community partner actually interacts with the students, and I think that's a critical component for the learning that our students are actually getting for them to actually interact with the partner."

Compared to "academic" projects in which the students provide only virtual deliverables or physical embodiments for a "virtual" customer, LTS projects typically result in hardware being fully implemented for the community partner. Accordingly, the LTS faculty practitioners have recognized that feedback from the community partners through direct interaction was necessary to ensure that the appropriate design was developed to address the needs of the community. This feedback often resulted in significant design changes that could have been overlooked otherwise. LTS provides a effective methodology to validate engineering solutions with feedback provided in an iterative development process.

In addition, the LTS faculty practitioners recognized that in order to co-create with the community towards the fulfillment of a successful engineering project, it is essential to view the community as willing partners rather than passive subjects upon whom the project is imposed upon and to whom the project deliverables are given.

\section{3) Engage Community Partners from an Asset-Based Viewpoint}

Another key principle that emerged from the faculty interviews was the opportunity for getting direct assistance from their community partners. One faculty states:

"I think our community partners are a tremendous resource and an often overlooked resource and give us a lot of free labor and expertise."

Another respondent stated:

"They don't have the content knowledge in order to really help us with a project, but they help us identify the need... something that obviously we don't have knowledge of."

From an engineering perspective, the community partners provide the most important requirements of the design. Many of these requirements are communicated in a non-technical nature or as only "latent needs." However, the conversion of the community partners' latent knowledge and "latent needs" to a formal specification is a critical first step that many, if not most, engineering students do not encounter until after graduation. Accordingly, these results 
suggest that engaging community partners as an asset to be cultivated and cherished is critical to the development of long-term, sustainable LTS efforts.

\section{4) Use Cultural Intermediaries in International LTS Efforts}

For faculty involved in international LTS efforts, working with a cultural intermediary was often viewed as essential. One faculty member states:

"[A] bi-cultural liaison is very important. Somebody who understands the American mindset as well as for example the Malian mindset or the Haitian mindset and someone who can maneuver between the cultures very easily is very helpful. That's one of my key takeaways from working in culture other than my own is to have somebody that I trust that's my, I call it my bi-cultural liaison."

Another faculty articulates the same view:

"[We] place a lot of emphasis on interacting with a community partner, and we always have at least one liaison with the community organizations with whom we're working who can help educate students about their organization and about the social needs that they need."

These faculty members understood that cultures vary across different parts of the world, in terms of meanings, language, and symbols. In order to understand another culture, it is important to understand what the community's values, traditions, and beliefs. The use of a highly involved and familiar cultural intermediary provides for more rapid and candid feedback; the alternative offers for items lost in translation as well as other details never offered due to cultural and other interpersonal barriers. As such, the use of a cultural intermediary increases the ability to receive more detail and clarity on the needs of the people being served. In understanding the culture of others through the lens of those who are part of the culture, the LTS faculty and student practitioners are better able to understand their own cultural values, beliefs, and norms. With respect to engineering education and practice, the differences between the LTS practitioner and community cultures are internalized such that implicit assumptions made regarding the engineering design are made explicit or changed altogether.

\section{5) Deliver Useful Projects}

The faculty respondents were aware of the fact that by understanding the needs of the community, through community feedback, the projects are likely to be useful to the community partner. One faculty states:

"You can make the coolest thing in the world for this homeless shelter but if it doesn't address the users' needs, what's the point. So that's what we really emphasize: they have to do volunteer hours at the site, they have to interview people, they have to get a proposal signed off by the client. So we really push that relationship building and being aware of the other person's needs."

The above view is also supported by another faculty:

"It really helps to change the situation of the people in the community, particularly those people in those communities that are disempowered and marginalized...So to me that's the number one criteria or should be the number one benefit is when the most disenfranchised, marginalized people in that community actually benefit from an intervention." 
The success of the partnership is based largely on the extent to which the partners' needs are met. The project can become futile or pointless without a careful understanding of the needs of the partners and the incorporation of those partners' needs into the design process. Therefore, it is essential to the sustainability of the partnership to meet the needs of the community partners for which the outcome is the delivery of useful projects.

\section{6) Sustain Relationships to Improve Long-Term Project Outcomes}

The importance of long-term commitment also became evident with respect to trust, management of risk or expectations, and the quality of the project outcomes. One faculty states:

"[We] implemented another phase in 2009 and then again in 2010, 2011, 2012, so there's kind of been a long process to this - I think there's been a lot of feedback cooperated throughout that. I think that really makes the case for the need for long-term partnerships with communities because our experience has been, with our relationship when we first got started, everybody was excited, it was phenomenal and then I think there was kind of a letdown after the reality of, our capabilities and their capabilities and everybody's expectations might have been dashed a little bit."

Another faculty states:

"One of the issues with the international service learning that I am involved with is it takes a long time to get to know a community and for the community to trust you. And you don't see them very often. One of the models that I like that I am hearing from other institutions is people go for much longer periods of time and try to work closer with the community."

It is clear from these interviews that sustained commitment is required from both academic and community partners. The commitment of both parties can be tested when significant issues arise with the implementation of engineering projects. Overcoming these challenges can lead to increased future commitment and stronger long-term relationships. Conversely, failed projects can reduce the level of commitment such that future projects will require relationship reparations and more formal and improved project planning.

\section{DISCUSSION}

The analysis of the above research is framed by the concept of a "community of practice" (CoP). The findings point to the fact that LTS provides opportunity for design courses and extracurricular programs to understand the needs of the community. One way to facilitate this process is to engage faculty, students, and community partners in a CoP. This collaborative learning approach to teaching and learning enables students to work with peers, faculty, and community partners to work together to solve problems and understand complex concepts. ${ }^{48}$ LTS experiences should be designed to ensure that students are empowered to respond to a community issue by highlighting a need, and by providing useful information to address a community issue. As such, students should be required to directly engage and learn with community members. Through interaction with the community, students were expected to be able to identify community problems and develop solutions within specific community context.

Within the context of CoP, another important finding is to seek community feedback through direct interaction. By seeking feedback from community partners students learn to develop intricate understanding of community problems through the lens of the community. Equally 
important, it involves community partners in the learning process with students. In a broader context, this pedagogical approach enabled the participants to engage in collaborative learning that is consistent with what Smith refers to as collective intelligence. ${ }^{49}$ In this epistemological framework, the participants come together in focused learning environments to provide the opportunity to blend their thinking into "oneness." Invariably, the participants demonstrated an understanding of the usefulness of mutually beneficial exchange of knowledge and resources with their community partners while responding to the social and economic needs of the communities they serve. From this standpoint, the community partners are viewed as having assets that are also important to contributing to the learning process.

Additionally, LTS practitioners demonstrated a common interest to increase their students' ability to learn about the culture of their community partners. The faculty members understand that their teaching interests are unlikely to succeed without fully understanding the culture of the people in the communities they serve. Therefore, engaging cultural intermediaries in international LTS efforts provide a medium for the sharing and creating of knowledge to solve real world problems. Interestingly, by virtue of the human-design process and the nature of the extra-curricular activities, the faculty members understand that the outcome of an authentic community partnership is the delivery of useful projects to the community. From the perspective of LTS faculty members it is necessary to directly engage students with members of the community to successfully develop solutions that address the needs of the community. Although project sites varied between local and international communities, the essential elements of effective community engagement remained consistent. There were no discernible differences between working in a local urban community (for example, on a community gardening project to measure contaminant concentrations in soil and water) and international LTS efforts (for example, in a poor village in Mali, where a project was designed to increase a community's income and add value to products such as post-harvest technologies). The important link to all of the projects is that the LTS efforts were designed to situate learning outside the classroom that facilitated the delivery of useful projects to the community.

Finally, LTS practitioners realize the importance of sustaining community partnerships in order to have a transformative relationship. Rather than focus on one-time projects, the relationship with community partners is interdependent in shedding light on onging social problems and seeking possible solutions to address the larger, underlying problems.

In conclusion, LTS efforts were structured around democratic learner-centered teaching, and viewing the community partner as having valuable resources in the learning process. The projects were designed to utilize the assets that the community members, students, and faculty member brought to the learning process. The faculty practitioners intentionally ensured that the community as well as students had a voice in the learning process by helping students break through their assumptions about the community around them. Hence, students were expected to recognize that the community has much to offer in terms of the strength and knowledge everyone brings to the learning process. By integrating asset-based instruction in LTS projects, students can fully understand the needs of the community and collaboratively develop solutions that address such needs.

\section{Recommendations for Future Research}

This study was designed to help fill the gap in understanding how LTS faculty practitioners in engineering engage with community partners to implement effective LTS experiences for 
students, identify the effective strategies for engaging community partners, and discover how LTS faculty practitioners and community partners engage to establish an effective LTS community of practice. A major limitation is that this research relies strictly upon faculty interviews and so primarily considers the faculty perspectives. Future research is recommended that investigates the community perspectives to fully understand the democratic or reciprocal nature of the relationship between higher education and their community partners.

\section{Implications}

The Carnegie Classification for Community Engagement is an important contrast to the notion that higher education is the lone expert who can solve community problems. Engagement in the community in a collaborative way suggests a realization that knowledge can be co-produced with the community as equal partner. The LTS faculty practitioners in this study have made some significant strides especially with respect to their design courses to engage their community partners in the co-creation of knowledge.

However, if LTS practitioners want to affect larger societal issues, they have to prepare students to take action beyond technical solutions. Indeed, faculty and students must also address the underlying and profound structural problems. While exposing students to community-based projects helps them understand the problems faced in the community in a deeper and more meaningful way, it does very little to increase students' influence in addressing the root causes.

\section{ACKNOWLEDGEMENTS}

The EFELTS effort, and the workshop material presented in this paper, is supported by the National Science Foundation under Grant Nos. 1022927, 1022883, 1022738, 1023022, and 1022831. Any opinions, findings, and conclusions or recommendations expressed in this material are those of the author(s) and do not necessarily reflect the views of the National Science Foundation.

\section{REFERENCES}

\footnotetext{
${ }^{1}$ Kellogg Commission on the Future of State and Land-Grant Institutions ( 1996) Returning to Our Roots: The Students Experience. Washington, DC: Natioanl Association of State Universities and Land-Grant Colleges.

${ }^{2}$ Chickering, A. \&Stamm, L. (2002) May /June, Making our Purpose Clear About Campus 7

${ }^{3}$ Driscoll, A. (2008) Carnegie's Community-Engagement Classification: Intentions and InsightsChange, JanuaryFebruary 2008 p. 39-41

${ }^{4}$ Hess, Deborah J., Hilreth Lanig, and Winston Vaughan. "Educating for equity and social justice: A conceptual model for cultural engagement." Multicultural Perspectives 9, no. 1 (2007): 32-39.

5 Strand, Kerry J. "Community-based Research as Pedagogy." Michigan Journal of Community Service Learning 7 (2000): 85-96.

${ }^{6}$ National Academy of Engineering (NAE) (2005) Educating the Engineer of 2020:Adopting Engineering Education to the New Century. Washington. The National Academies Press.

${ }^{7}$ National Science Foundation (NSF) 2007 Moving Forward to Improve Engineering Education (No NSB-07-122) Washington, DC: National Science Foundation

${ }^{8}$ National Academy of Engineering, Educating the Engineer of 2020. 2005. National Academic Press.
} 
${ }^{9}$ Bielefeldt, A.\& Pearce, J. in Colledge (Ed.) (2012) Convergence: Philosophies and Pedagogies for Developing the Next Generation of Humanitarian Engineers and Social Entrepreneurs. International Journal for ServiceLearning in Engineering.

${ }^{10}$ Tsang, E. (Ed.). 2000. Projects that matter. Concepts and models for service-learning in engineering.Washington DC. AAHE

${ }^{11}$ Peters, S., Educating the Civic Professional: Reconfigurations and Resitances. Michigan Journal of Community Service-learning, Vol 11 (11), Fall 2004.

${ }^{12}$ Bringle, R. G., \& Hatcher, J. A. (1995) A Service-Learning Curriculum for Faculty, The Michigan Journal of Community Service-Learning, Fall, 1995, pp.112-122

13 Jacoby, B. (1996) Service-learning in today's higher education. In B. Jocoby and Associates. (Eds.) ServiceLearning in Higher Education: Concepts and Practices. San Francisco: John Wiley \& Sons/ Jossey Bass

${ }^{14}$ Morton, K. \&Troppe, M. (1996). From margin to Mainstream: Campus Compact's project on integrating service with academic study. Two cases of institutionalizing service-Learning: How campus climate affects the change process. Providence: Campus Compact.

${ }^{15}$ Marullo, S. (1997). “The Service_Learning Movement in Higher Education: An American Response to Troubled Times."Sociological Imagination 33: 117-137

${ }^{16}$ Erickson, J., \& Anderson, editors (1997) Learning with the Community, Concepts and Models for ServiceLearning in Teacher Education, Washington, D.C. American Association for Higher Education.

${ }^{17}$ Stanton, T., Giles, D. Jr., and Cruz, N. (1999) Service-Learning: A Movement's Pioneers Reflect on its Origins, Practice and Future. San Francisco, CA: Jossey-Bass

${ }^{18}$ Bielefeldt, A.\& Pearce, J. in Colledge (Ed.) (2012) Convergence: Philosophies and Pedagogies for Developing the Next Generation of Humanitarian Engineers and Social Entrepreneurs. International Journal for ServiceLearning in Engineering

${ }^{19}$ Colby, A. Ehrlich, T., Baumont, E., \& Stephen, J. (2003) Educating Citizens: Preparing America’s Undergraduates for Lives of Moral and Civic Responsibilities, San Francisco, CA: Jossey-Bass

${ }^{20}$ Howard, Jeffrey. "Service-learning research: Foundational issues." Studying service-learning: Innovations in education research methodology (2003): 1-12, pp. 23.

${ }^{21}$ Hepburn, M. A., (2000) Service-learning and Civic Education in the Schools: What Does Recent Research Tell Us?.In Mann, S. \& Patrick, J. J. (Eds.) Education for Civic Engagement in Democracy, Service-learning and other Promising Practices. pp. 47.

${ }^{22}$ Enos, Sandra L., and Marie L. Troppe. "Service-learning in the curriculum."Service-learning in higher education. San Francisco: Jossey-Bass (1996): 156-181.

${ }^{23}$ Giles, D \& Eyler, J.(1994) The Theoretical Roots of Service-Learning in John Dewey: Toward a Theory of Service-learning,Michigan Journal of Community Service-learning, Vol 1. Issue 1 77-85

${ }^{24}$ Dewey, J. (1929). Experience and Nature. London: George Allen \&Unwin, Ltd.

${ }^{25}$ Campbell, James. Understanding John Dewey: nature and cooperative intelligence. Open Court Publishing, 1995.

${ }^{26}$ Boisvert, R. D. (1998). John Dewey: Rethinking our time. Albany, NY: State University of New York Press.

${ }^{27}$ Campbell, James. Understanding John Dewey: nature and cooperative intelligence. Open Court Publishing, 1995.

${ }^{28}$ Huilmanet at, (2005) Service-learning in engineering: a valuable pedagogy for meeting learning objectives Journal of Engineering Education Vol. 30 No. 2 May 2005, pp. 155-165.

${ }^{29}$ Colby, A. Ehrlich, T., Baumont, E., \& Stephen, J. (2003) Educating Citizens: Preparing America’s Undergraduates for Lives of Moral and Civic Responsibilities, San Francisco, CA: Jossey-Bass

${ }^{30}$ Lima, M. \& Oakes, W. (2006) Service-Learning Engineering in the Community. Great Lakes Press, Inc.

${ }^{31}$ Colledge, T. (Ed.) ( 2012) Convergence: Philosophies and Pedagogies for Developing the Next Generation of Humanitarian Engineers and Social Entrepreneurs. International Journal for Service-Learning in Engineering

${ }^{32}$ Vanasupa, L., Slivovski, L., \& Chen, K.C. (2006) Global Challenges as Inspiration: A Classroom strategy to foster social responsibility. Science and Engineering Ethics, 12(2), 373-380

${ }^{33}$ Johnson, D., Johnson, R., \& Smith, K. (1991) Cooperative Learning.HSHE-ERIC Higher Education Reports, Washington, D.C. The George Washington University, School of Education Human Development

${ }^{34}$ Barr, R. B., \&Tagg, J.A New Paradigm for Undergraduate Education in November/December 1995, Change Magazine.

${ }^{35}$ Etienne, Wenger, Richard Arnold MacDermott, and William M. Snyder.Cultivating communities of practice: A guide to managing knowledge. Harvard Business Press, 2002. 
${ }^{36}$ Vygotsky, L.S., 1978, Mind in society: The development of higher psychological processes, Cambridge, MA: Harvard University Press

${ }^{37}$ Wenger, E., 1998, Communities of practice: Learning, meaning and identity, Cambridge: Cambridge University Press.

${ }^{38}$ Lave, J., \& Wenger, E. (1991) Situated learning: Legitimate peripheral participation. Cambridge, UK: Cambridge University Press

${ }^{39}$ Lyons, Nona, and Vicki Kubler LaBoskey, eds. Narrative inquiry in practice: Advancing the knowledge of teaching. Vol. 22. Teachers College Press, 2002.

${ }^{40}$ Aslam, A., Pearson-Beck, M., Boots, R., Mayton, H., Link, S., Elzey, D., (20013) Effective Community Listening: A Case Study on Photovoice in Rural Nicaragua, International Journal for Service Learning in Engineering Vol. 8, No. 1, pp.36-47, Spring 2013

${ }^{41}$ Leight, K., \& Clevenger, C. M. (2013) Service_Learning Cross_Cultural Collaboration: Sustainable Actions in an Elementary School, Bagaces, Costa Rica, International Journal for Service Learning in Engineering, Vol. 8, No. 1, pp. 102-115, Spring 2013

${ }^{42}$ Duffy, J. (2008) Village Empowerment: Service-Learning with Continuity, International Journal for Service Learning in Engineering, Vol. 3, No 2. Pp1-17 Fall 2008

${ }^{43}$ Merriam, S. B. (1998). Qualitative research and case study applications in education. San Francisco, CA: JosseyBass Publishers, pp. 27.

${ }^{44}$ Yin, R. K. (2003) Applications of case study research. Thousand Oaks: Sage Publications.

${ }^{45}$ Merriam, S. B. (1998). Qualitative research and case study applications in education. San Francisco, CA: JosseyBass Publishers, pp. 27.

${ }^{46}$ Attride-Stirling, Jennifer. "Thematic networks: an analytic tool for qualitative research." Qualitative research 1 , no. 3 (2001): 385-405.

47 Zoltowski, Carla B., William C. Oakes, and Monica E. Cardella. "Students' Ways of Experiencing Human-Centered Design." Journal of Engineering Education 101, no. 1 (2012): 28-59.

${ }^{48}$ Pierrakos, Olga, Anna Zilberberg, and Robin Anderson. "Understanding undergraduate research experiences through the lens of problem-based learning: Implications for curriculum translation." Interdisciplinary Journal of Problem-based Learning 4, no. 2 (2010): 4.

${ }^{49}$ Smith, J. B. (1994) Collective intelligence in computer-based collaboration. Hillsdale, NJ: Lawrence Erlbbaum. 